\title{
STATISTICAL ANALYSIS IN PARAPLEGIA
}

\author{
By W. G. KERR, F.R.C.S.E. \\ Spinal Injury Centre, Edenhall Hospital, Musselburgh, Scotland
}

THE introduction of electronically controlled data processing machines has greatly simplified the recording and collation of information and this statistical method is being increasingly used in medicine. Medical records contain a vast amount of detail and considerable time and energy can be spent in a search through these records to obtain information for research or as a guide to the treatment of future patients.

Guttmann (I953) has stressed the need for international agreement with regard to statistical work on paraplegics to ensure proper comparison in the future. International agreement on so complicated a subject may be hard to obtain and, for some time, each centre will continue to use its own methods. The method described below is similar to that used in the British limb-fitting service and as described by Campbell, Noall and Hopkins (1964) at the Scientific Exhibition of the American Academy of Orthopaedic Surgeons in Chicago. It has been in use at Edenhall for the past year. The data for all new cases can be recorded in a matter of minutes before the patient's discharge and work is slowly progressing in the recording of data relating to all former patients.

Accuracy in recording is absolutely essential as a machine can only reflect the accuracy of the material fed into it and, for this purpose, cross-checking by a medical colleague is highly desirable.

Preparation of Records. The final record consists of an 80-column punch card (fig. I), each column representing a specific category of information, as shown on data sheets (figs. 2 and 3 ). Each number in the column represents the particular

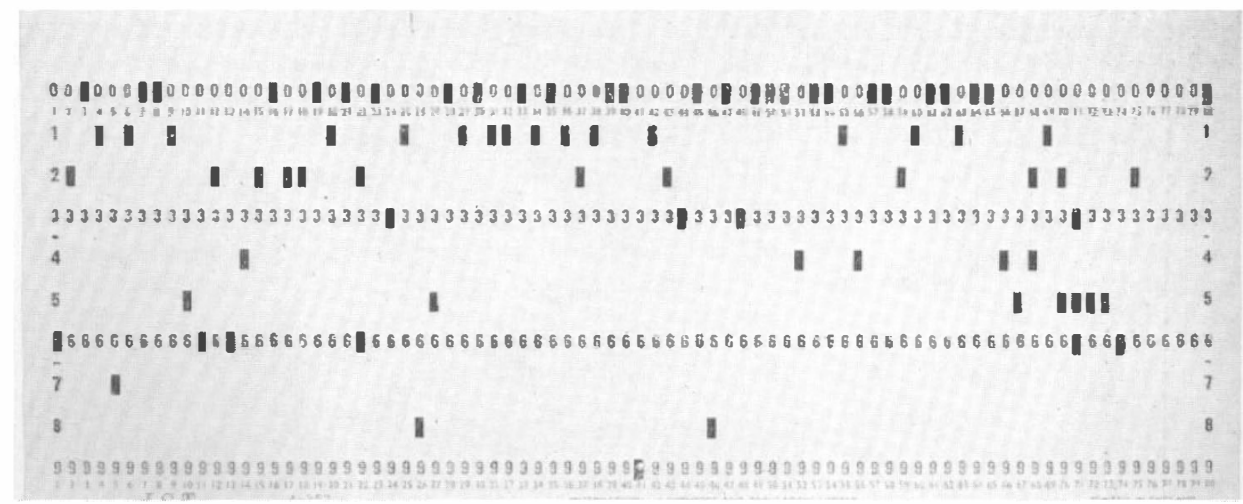

FIG I

Completed data processing card.

variable or variables relating to the patient. It is remarkable how many categories and variables can be related to a paraplegic, and it has been found necessary to exclude a few categories recommended by consultant colleagues and, on occasion, to place two allied categories in the same column. It is felt, however, that most items 
INITIAL

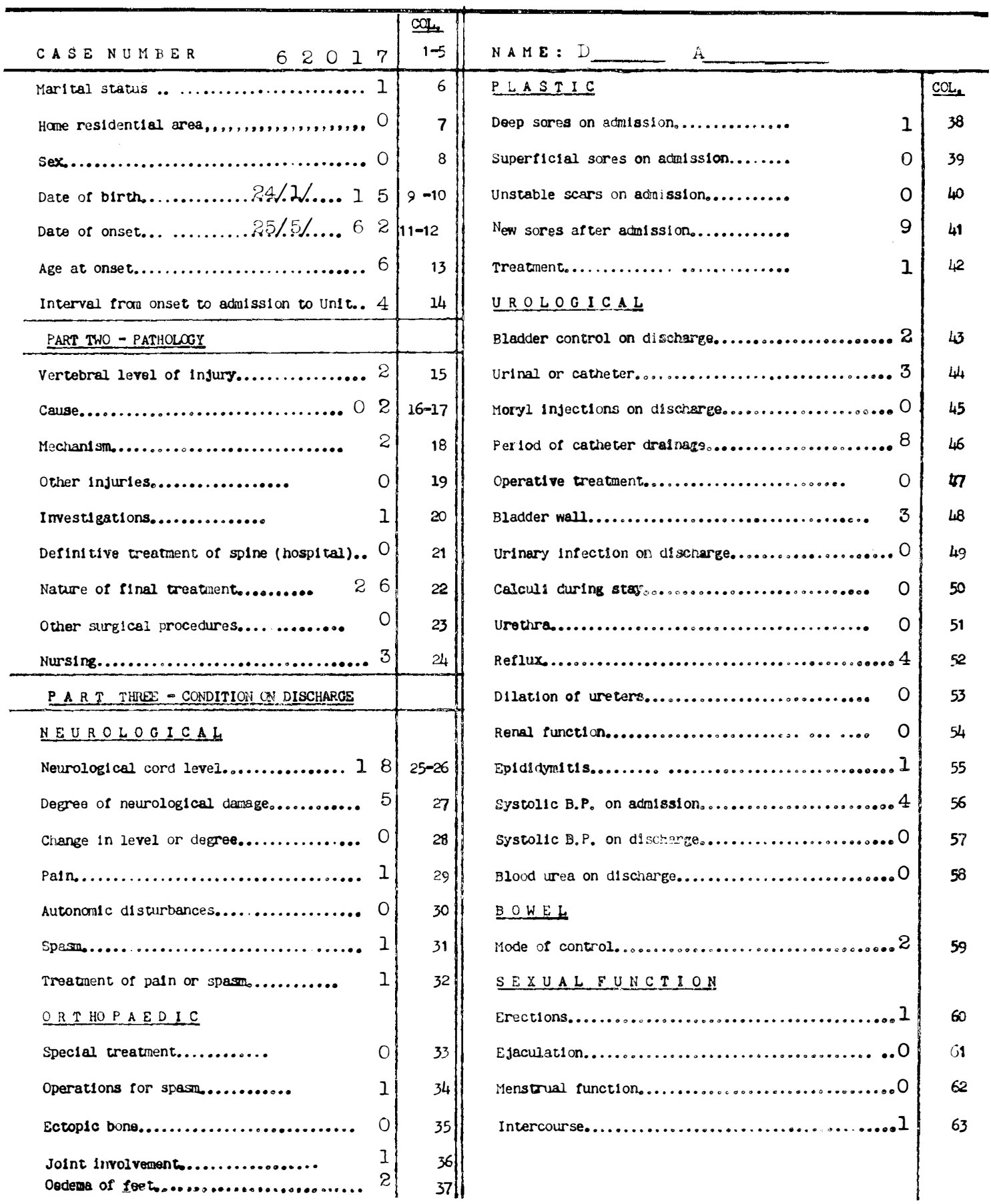

FIG. 2. Completed data sheet from which Figure I was prepared. 


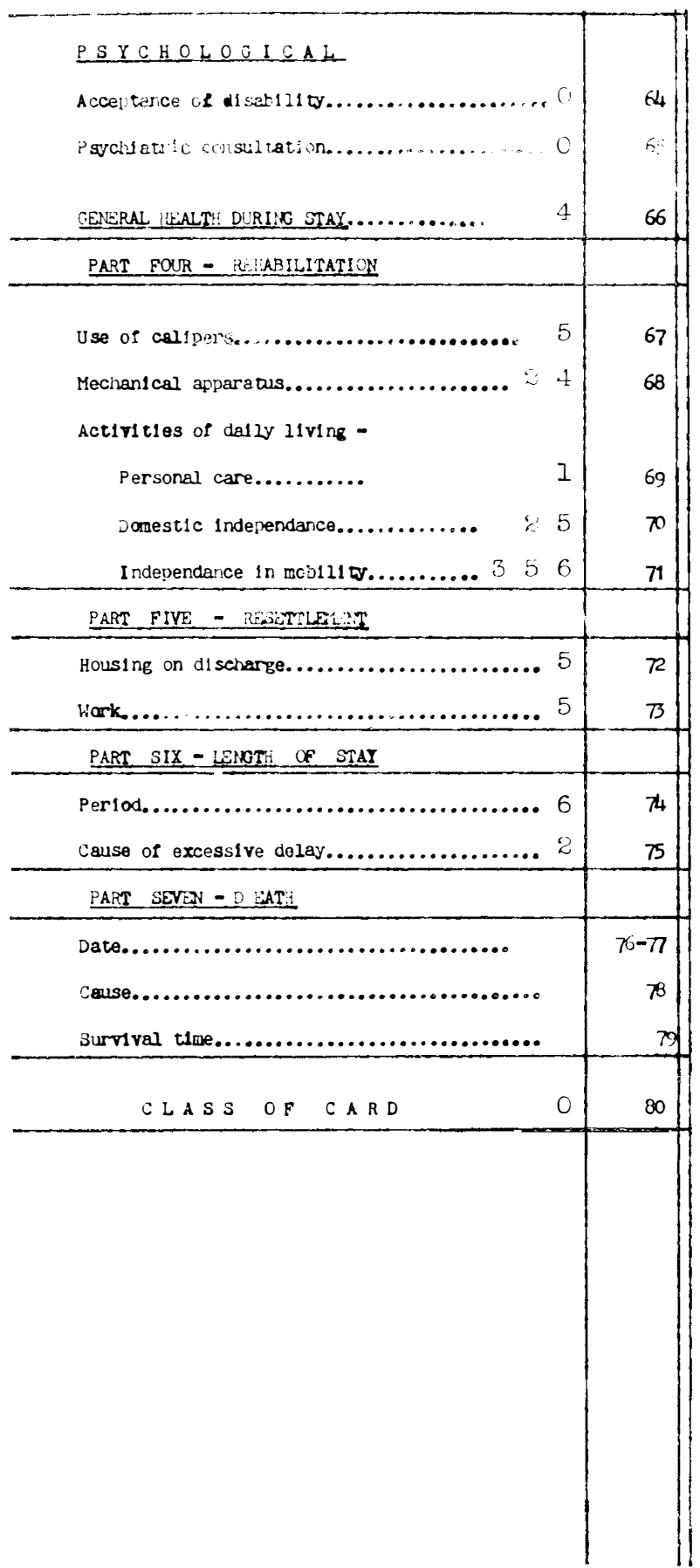

FIG. 3

Completed data sheet from which Figure I was prepared. 
of importance have been included and that there were not sufficient omissions to justify the use of two cards for each patient, giving I60 columns.

The figure to be inserted in the data sheet is obtained from a code sheet. This consists of five sheets of foolscap and, for reasons of space, cannot be included in an article of this nature. Two examples are, however, given (fig. 4) and copies of the full sheet can be supplied by the author if desired. Minor amendments to the code

Degree of Neurological Damage (Col. 27)

Cervical cord lesion

Complete

Minor Tract sparing

Major Tract sparing

Central Cord Syndrome

Full cord recovery

Non-Cervical cord lesion

Complete .

Minor root escape

Major root escape

Incomplete cord lesion

Roots only

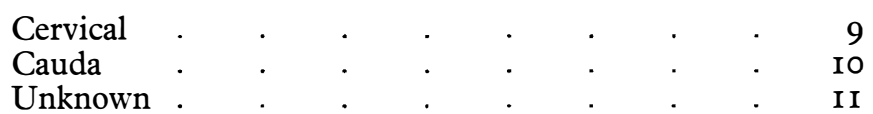

DeEp Sores on or Before Admission (Col. 38)

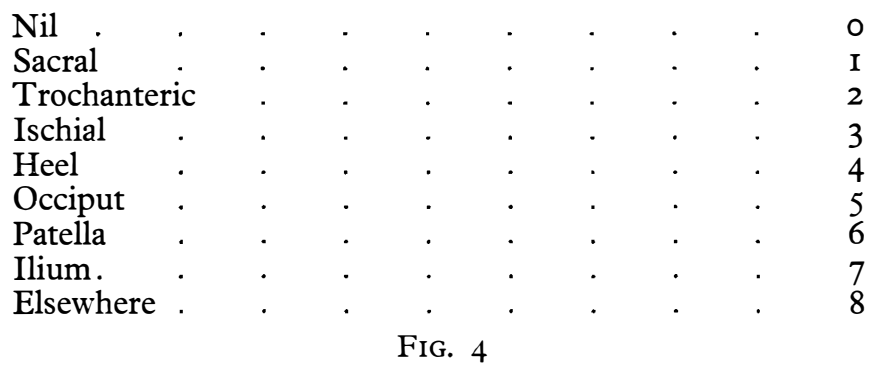

Examples of code references taken from the initial code sheet.

sheet were made in the early stages but it must be realised that any future amendment would necessitate amendment to all previously prepared data sheets and cards.

In the preparation of the data sheets care has been taken to include negative information or to record that the information required is not available. This ensures the separation of 'nils' from the 'unknowns' and, as a result, a completed initial data sheet should have at least one entry for every category except, in the majority of cases, for columns 76-79 relating to the ultimate death of the patient.

More than one entry can be inserted in a column if necessary and the information desired from the data processing machine can be obtained simply by passing the relevant cards through more than once. In a trial run of the first two dozen completed record cards it was found, for example, that I I were traumatic thoracolumbar cases and of these eight were admitted with no pressure sores, one with a superficial heel sore, one with a deep sacral sore and one with multiple sores. Exam- 
ination of this card showed that the sores were on the sacrum, iliac crest and patella. Further details with regard to this or any other patient can be obtained by referring back to the case notes, the five-figure number being shown in columns $I-5$.

Reviews. It will be noted that column 80 refers to the 'class of card'. An ' $O$ ' in this column signifies that the card relates to the initial care of the patient. Another code sheet has been prepared for recording the patient's progress at periodic intervals after injury or onset. Only 40 columns are used for each review, card ' $I$ ' relating to reviews at one and two years, card ' 2 ' to reviews at five and ten years and card ' 3 ' to reviews at 20 and 30 years after injury or onset.

A patient may be first seen many years after onset or may still be undergoing initial treatment when a periodic review becomes due. Allowance is made for this in columns 9 and 46 of the review code sheet. This column is headed 'Review carried out or not' and gives a choice of seven reasons for failure. The figure ' 3 ' refers to the circumstance referred to above and is titled 'anachronistic'.

The other review columns refer to any alterations in marital state or residential area and any change in clinical state, improvement or deterioration in the activities of daily living, or changes in housing, work, etc. In some cases detail such as the site of new sores or the development of reflux can be recorded but, in other categories such as housing or mobility, a simple statement of 'unchanged, deteriorated or improved' is all that has been allowed for. If further details are required the card again gives ready reference to the relevant case notes for further study.

\section{SUMMARY}

Rapid reference to statistical information is invaluable for research and for the proper study of the clinical aspects, rehabilitation and resettlement of patients.

A description is given of a method of obtaining this information by the use of 80 -column data processing cards.

\section{RÉSUMÉ}

Une référence rapide à l'information statistique s'est montrée d'une très grande valeur en ce qui concerne la recherche, l'étude des aspects cliniques, la réadaptation fonctionnalle et professionnelle des malades.

Une description de cartes de référence est donnée.

\section{ZUSAMMENFASSUNG}

Schnelle statistische Information ist von grösster Wichtigkeit für wissenschaftliche Forschung und für das Studium klinischer Probleme, Rehabilitation und Wiedereingliederung von Patienten.

Eine Methode für solch eine Information ist beschrieben.

\section{ACKNOWLEDGEMENTS}

I wish to acknowledge the help and encouragement received from the visiting Consultants to the Spinal Injury Unit and, in particular, the assistance given by Mr. D. F. Hardman of the Data Processing Department of the Regional Hospital Board.

\section{REFERENCES}

Campbell, P., Noall, L. \& Hopkins, R. (1964). F. Bone F. Surg. 46A, i I40. Guttmann, L. (1953). In History of the Second World War, U.K. Medical Series, Surgery, p. 422. Ed. Cope, Sir Zachary. London: H.M.S.O. 